\title{
A reappraisal of instrumental magnetic measurements made in Western Europe before AD 1750: confronting historical geomagnetism and archeomagnetism
}

\author{
Maxime Le Goff* ${ }^{*}$ and Yves Gallet
}

\begin{abstract}
We present a new compilation and analysis of historical geomagnetic measurements made in Western Europe before AD 1750. The dataset in its ensemble provides a coherent evolution of magnetic field directions. Several data points excluded from previous analyses actually appear very consistent with most of the present compilation. A new average historical curve is computed for Paris, which is in very good agreement with the archeomagnetic data obtained in France, while significantly differing from the directional curve expected for Paris before AD 1675 based on the gufm 1 model (Jackson et al. in Philos Trans R Soc Lond A 358:957-990, 2000). This finding suggests that the older segment of the gufm 1 model lacks reliability and should be improved. Similarly, the historical part of the regional geomagnetic field model built for Europe by Pavón-Carrasco et al. (Geochem Geophys Geosyst 10:Q03013, 2009) should be revised because it erroneously incorporates directions derived from the gufm 1 model.
\end{abstract}

Keywords: Historical magnetism, Archeomagnetism, Secular variation, Geomagnetic directions, Western Europe

\section{Introduction}

Since the dawn of archeomagnetic research, data obtained in Europe from archeological artifacts and volcanic deposits were used to build regional-scale geomagnetic directional secular variation curves (e.g., Chevalier 1925; Aitken and Hawley 1966; Tanguy 1969; Thellier $1966,1981)$. An issue rapidly arose regarding the continuity between archeo-/paleomagnetic results and the most ancient instrumental or "direct" measurements of declinations $(D)$ and inclinations $(I)$. In Western Europe, magnetic declinations have been directly measured since the middle of the sixteenth century, whereas only a very small number of inclination data became available more than a century later (e.g., Jackson et al. 2000; Jonkers et al. 2003). These series of pioneering $D$ and $I$ measurements from the sixteenth and seventeenth centuries, especially those obtained in London and in Paris, were the subject

*Correspondence: legoff@ipgp.fr

Institut de Physique du Globe de Paris, Sorbonne Paris Cité, UMR 7154 CNRS, Université Paris Diderot, Paris, France of several compilations (e.g., Malin and Bullard 1981; Alexandrescu et al. 1996, 1997). Comprehensive datasets further incorporating measurements reported in ship logbooks by mariners during their navigation around the world have been used to construct global geomagnetic field models encompassing the past four centuries, in the form of Gauss coefficient time series. At present, the gufm 1 model developed by Jackson et al. (2000) is used most frequently. It enabled, in particular, studies to decipher the evolution of the main core flow patterns at the core surface (e.g., Hulot et al. 2002; Holme 2007; Finlay et al. 2016). Note that the first examples of global reconstruction of the ancient field date back to the nineteenth century; one can, for instance, mention the work of the Swedish scholar Carlheim-Gillensköld (1896), whose computations went back to the sixteenth century. More recently, a regional field model was also constructed for Europe using a spherical cap harmonic (SCHA) analysis technique incorporating both archeomagnetic and historical geomagnetic data (Pavón-Carrasco et al. 2009). 
In addition to the construction of global or regional geomagnetic field models, instrumental measurements were also used to extend the directional geomagnetic field variation curves derived from archeomagnetic data. Using a compilation of direct data from Paris, London and Rome, Thellier (1981) traced the oval characterizing the directional variations in Western Europe during the historical period (back to 1600; dark-blue curve in Fig. 1), which according to Thellier was "bien connu depuis plus d'un siècle" (well known for over a century). In Thellier's work, this oval revealed a nearperfect continuity with the French archeomagnetic data then available for the sixteenth and seventeenth centuries. This agreement was strengthened by additional archeomagnetic data obtained by Bucur (1994), who published the last compilation of French archeomagnetic data spanning the past two millennia. The orange curve in Fig. 1 displays the mean archeomagnetic directions between AD 1000 and 1550, as computed by
Bucur (1994), whose confidence ovals at 95\% were omitted for a better readability (the individual archeomagnetic data presently available between AD 1500 and 1700 are grayed out in Fig. 1; note further that some of them are still unpublished). Its continuity with the instrumental curve argues for a large clockwise loop of the geomagnetic directions since the middle of the fourteenth century. A striking observation, however, is that this good continuity is lost when the gufm 1 historical field model is used to compute the expected directional variations in Western Europe during the seventeenth century (white curve in Fig. 1). While the declination results are similar, the gufm 1 inclinations appear too high with respect to the mean archeomagnetic variation curve computed by Bucur (1994). Two other historical variation curves are also reported in Fig. 1: a brown curve derived from a global field model previously constructed by Thomson and Barraclough (1982), and a black curve computed by Malin and Bullard (1981) from

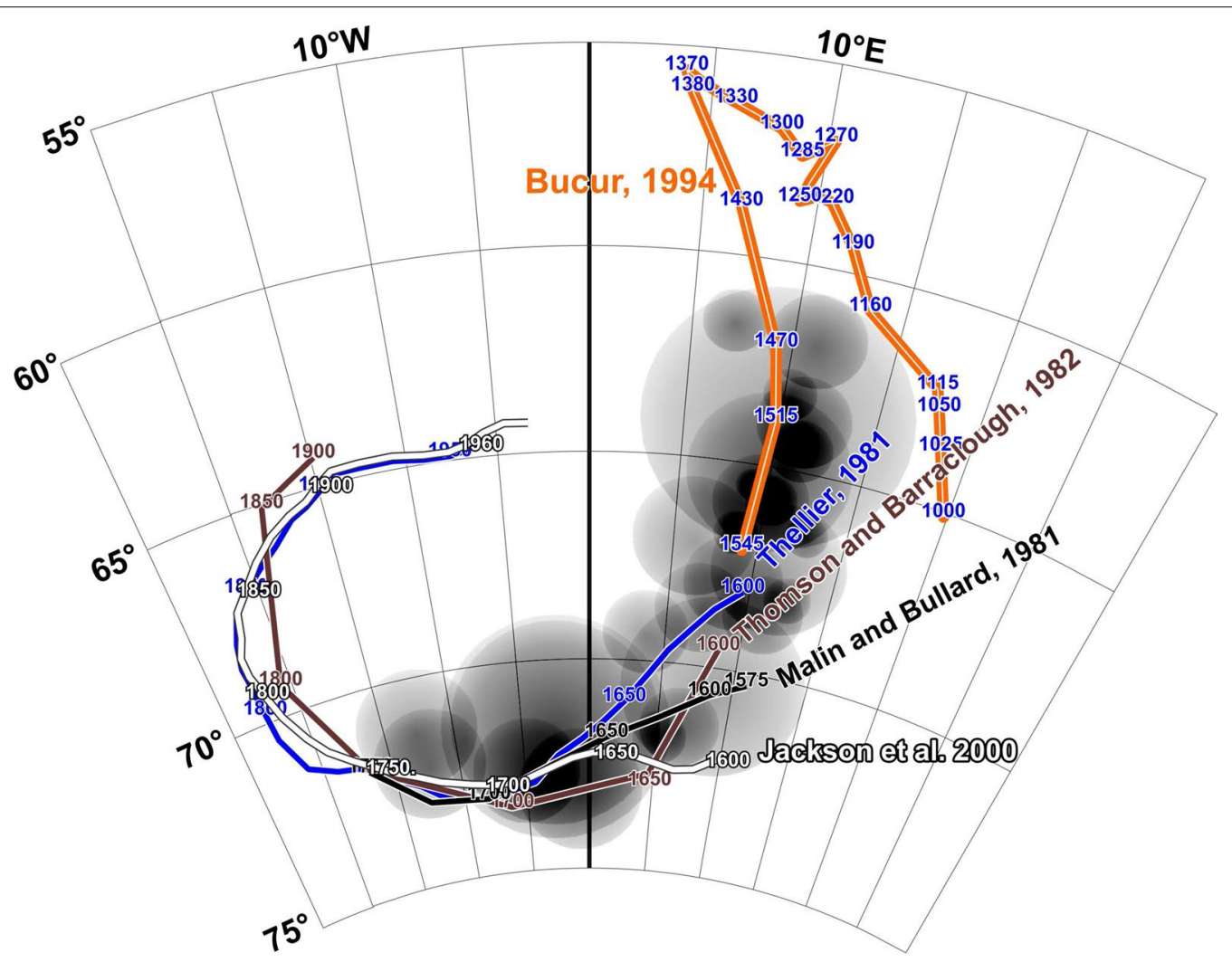

Fig. 1 Geomagnetic directional variations in Western Europe (all data reduced to Paris) over the past 1000 years as constrained from archeomagnetic results, direct historical magnetic measurements and field modeling. Individual archeomagnetic data from AD 1500 to 1700 are shown in gray, whereas the orange curve displays the average French archeomagnetic variation curve according to Bucur (1994). The dark-blue curve exhibits the historical geomagnetic variations spanning the past four centuries estimated at Paris by Thellier (1981) from a selection of $D, I$ measurements from Paris, London and Rome. The black curve from Malin and Bullard (1981) expresses the directional variations at Paris when considering only the $D$, I measurements made in London. The brown and white curves show the evolution in magnetic direction expected in Paris from two global field models constructed by Thomson and Barraclough (1982) and Jackson et al. (2000), respectively 
$D$ and $I$ values measured in London and its surroundings. These two curves happen to be in better agreement with the French archeomagnetic data than the expected curve from gufm 1 .

The objective of this study is to better constrain the continuity and/or compatibility between the earliest Western European instrumental directional data and the available French archeomagnetic results. For this purpose, we present a new analysis of the historical geomagnetic data spanning the AD 1500-1750 time interval. This analysis therefore provides a reliability test of the directions expected in Europe from gufm 1 and, as a consequence, for that of the older segment of the gufm1 model.

\section{Instrumental magnetic directional measurements in Western Europe before AD 1750}

The catalogs of historical instrumental magnetic measurements are subject to sporadic reviews. For the Western European region, practically all references can be found in the recent article of D'Ajello Caracciolo et al. (2011), whereas all records obtained worldwide contained in the global database used for the construction of the gufm 1 model (Jackson et al. 2000) are available on the Web (ftp://ftp.nmh.ac.uk/geomag/Shipborne/).

Instrumental inclination data are scarce before $\mathrm{AD}$ 1750, and perhaps approximate given the rudimentary design of instruments used at that time (see illustration, for instance, in Cabeo 1628 or Kircher 1641). Note also that the ancient writings often lacked precision on dates and/or locations of measurements (see below). However, it seems certain that the observers tried to make measurements as accurate as possible. Here we took into account these results without any unfavorable consideration. Whenever possible, we returned to the original documents written by the scholars of that time.

In the present study, we associated to the pre-1750 inclination data gathered in Western Europe the declinations simultaneously measured (if existing) or the values interpolated from the declination dataset available for the same location. Where inclinations were measured at an isolated site, declinations corresponding to the site provided by the gufm 1 model were assigned, assuming a good fit of declination data, which were already relatively numerous worldwide during the seventeenth century. We acknowledge that this approach is not flawless, but it appears reasonable, and there is no other means of estimating declinations at isolated locations during the sixteenth- to seventeenth-century time interval. All pre-1750 Western European data considered in the present study are reported in Table 1. Data were separated into two groups. The first group comprises values used by Emile Thellier (archives of his 1981 article) including datasets from London, Paris and Rome. The second group includes all other direct measurements found in the gufm1 global database.

\section{Examination of the available records}

All data listed in Table 1 were reported on an equal-area projection diagram after their reduction to a common site using virtual geomagnetic poles (Fig. 2); here the chosen site is Paris $\left(\lambda=48.9^{\circ} \mathrm{N}, \phi=2.3^{\circ} \mathrm{E}\right)$. Furthermore, in order to take into account possible small misalignment, these data are shown with an arbitrary angular error $\left(\alpha_{95}\right)$ of $1.0^{\circ}$ and $0.7^{\circ}$ for records pre- and post-dating AD 1700, respectively. These rough values are consistent with previous errors estimated by Jackson et al. (2000) and PavónCarrasco et al. (2009). The error was increased to $1.5^{\circ}$ for only two particular data that were derived from aurora curtains (see below).

Group 1 data from London compiled by Malin and Bullard (1981) are the most numerous and arguably the best documented (yellow circles in Fig. 2a with corresponding dates preceded by "L" for London). Most of the older London data were previously given very low or no weight for the construction of an average curve, mainly due to an ignorance of the context in which values were recorded (see Table 3 in Malin and Bullard 1981). However, one can see that apart from L1661 and L1684 their consistency is very satisfactory with a clear directional evolution toward the West and with slightly increasing inclinations. The French data compiled by Alexandrescu et al. (1996) are much less numerous (pink circles in Fig. 2a with dates preceded by "P" for Paris). P1660 and P1668 were disregarded by Alexandrescu et al. (1996) because they did not appear in agreement with the general directional trend defined by data from London (and also following a similar comment made by J. Raulin; see $\$ 6$ in Alexandrescu et al. 1996), whereas P1671 was retained. However, from Fig. 2a, one could easily argue for excluding P1671 while retaining P1660 and P1668. The unique and well-known measurement made in Rome by Athanase Kircher and consensually dated at 1640 (red circle labeled R1640 in Fig. 2a) is also in particularly good agreement with the directional trend seen from the London data. We note that in Kircher (1641), the inclination value is $65^{\circ} 50^{\prime}$ on page 401 , but $65^{\circ} 40^{\prime}$ on page 410 . Nevertheless, regarding the distribution of the data, we do not see any reason to reject this particular datum, in contrast with doubt raised by Lanza et al. (2005) and D'Ajello Caracciolo et al. (2011). The Italian dataset does not contain any other inclination value until the measurements made by Alexander von Humboldt in 1805-1806 (e.g., Cafarella et al. 1992).

Group 2 contains 16 other inclination data from Western Europe found in the global database and reported 
Table 1 Synthesis of the historical directional measurements from Western Europe compiled in the present study

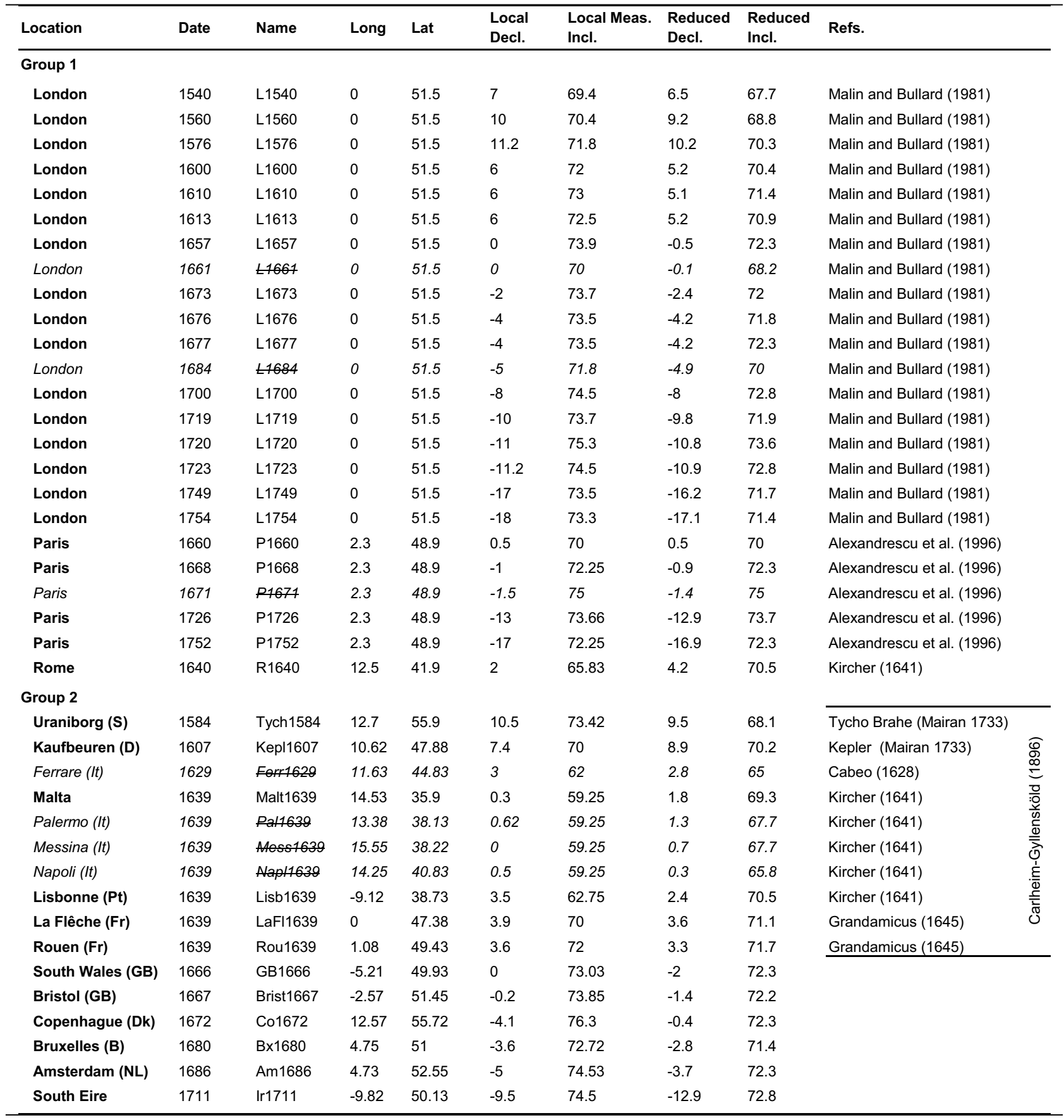

These data are separated into two groups. The first group contains the datasets from London, Paris and Rome, whereas the second group comprises additional data found in the gufm 1 global database. All declinations from the second group were estimated using the gufm 1 model (see text). Reduced decl. and incl. are the declinations and inclinations after transfer to Paris of the local directions using virtual geomagnetic poles. The data written in italics, and whose names are marked off, were eliminated from the computation in Paris of a new average historical geomagnetic directional variation curve valid for Western Europe

in Fig. 2b. Geographically, they are located in an area bounded by Malta to the south, Sweden (from the observatory Uraniborg created by Tycho Brahe) to the north, Ireland to the west and Bavaria, in Germany, to the East. In Fig. 2b, all declinations associated with the inclination data were estimated using the gufm1 model. It is worth mentioning that two inclinations dated at 1584 and 1607 obtained by astronomers Tycho Brahe and Johannes Kepler were deduced from the continuation to the Earth's surface of rays of aurora curtains 


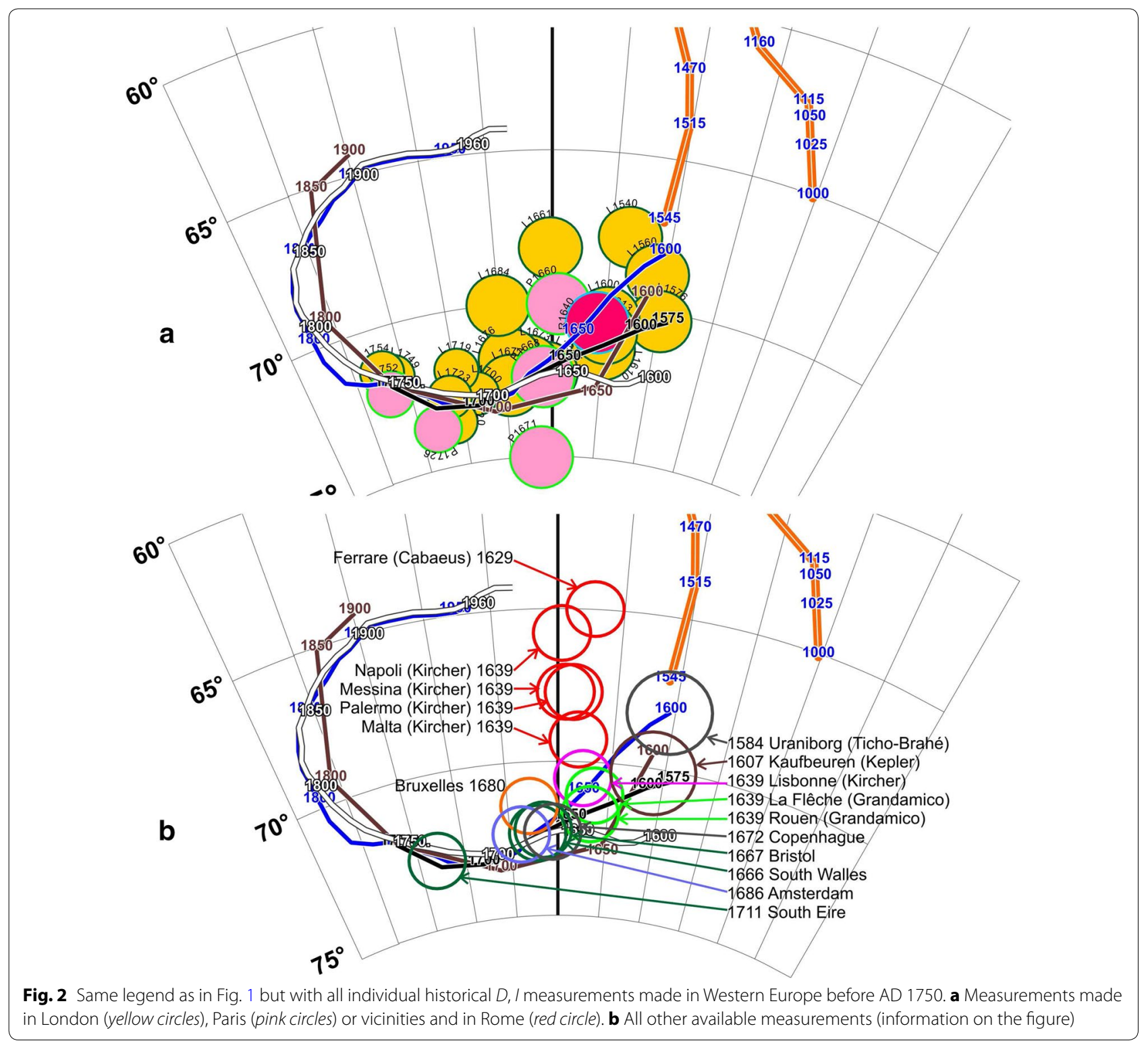

aligned following the local direction of the geomagnetic field (Mairan 1733; see page 29 in Carlheim-Gyllensköld 1896). It is remarkable to see how these two results lie close to the overall trend defined by most available data (Fig. 2a, b). In contrast, four data from Italy appear significantly distant from this trend. One of these records was reported from Ferrare by Cabeo (1628). It is curiously dated 1629, thus 1 year after Cabeo's publication. The three others are part of a group of four strictly identical inclination values $\left(59.25^{\circ}\right)$ all dated 1639 and reported by Kircher (1641) from Malta, Palermo, Messina and Napoli. None of them were listed in the Italian catalog of Cafarella et al. (1992), but were considered by Carlheim-Gyllensköld (1896). Their distinct positions in Fig. 2b originate from the effect of reduction to Paris because of the different latitudes of these cities. The original paragraph in which these values have been mentioned is ambiguous: Kircher (1641) wrote on page 401 that he went to Malta to perform a measurement, thus finding an inclination of $59.25^{\circ}$, but he did not say whether he went to the three other Italian cities to achieve other measurements. He only wrote that the three values were almost the same as the one measured in Malta, and from all the observations he knew at that time, he concluded that the inclinations were varying as a function of latitude, thus in contradiction with the data in question. Owing to this clear ambiguity, the present compilation retains only the inclination from Malta. 


\section{Discussion and concluding remarks}

Figure 3 exhibits together the 41 historical geomagnetic directions discussed above. Among these directions distributed between AD 1540 and 1754, seven values are excluded following the observations made in "Examination of the available records" section (dashed circles in Fig. 3 and data in italics in Table 1). The 34 remaining values define a very consistent directional evolution. Given the large geographical distribution of the data, such good consistency indicates that any non-dipole field effect across Western Europe most probably was very limited during the historical period. Otherwise, the reduction to Paris of the $D$ and $I$ values via virtual geomagnetic poles would have introduced a significant scatter in the transferred values. This evolution conforms to the curve previously proposed by Thellier (1981). This is further confirmed by the computation of an average curve using the method developed by Le Goff (1990) and Le Goff et al. (2002), which is shown in black-red in Fig. 3 (see results in Additional file 1: Fig. S1 and Table S1). It is worth recalling that this method relies on bivariate statistics and on sliding windows whose durations vary as a function of the temporal distribution of data. The only difference with Thellier's (1981) curve concerns a shift in time of the mean directions estimated during the sixteenth and the beginning of the seventeenth century, which is likely due to the fact that Emile Thellier essentially established a hand-drawn curve and considered a smaller number of data. Conversely, our new curve is significantly distant from the directional evolution expected at Paris from the gufm 1 model. Differences essentially concern the inclinations, as they are larger than the error bars estimated for the instrumental measurements, while they are weak enough to remain within the error bars estimated for the declination data (Additional file 1: Fig. $\mathrm{S} 1$ ). It is interesting to note that adding the seven data excluded from the computation would not reconcile the two curves. This likely indicates that the gufm 1 model does not faithfully reproduce the geomagnetic field evolution in Western Europe between the late sixteenth century and the seventeenth century and only does so from approximately 1675 onward (Fig. 3).

When now considering the European SCHA model constructed by Pavón-Carrasco et al. (2009) that combines both archeomagnetic and historical geomagnetic data, the directional evolution expected at Paris

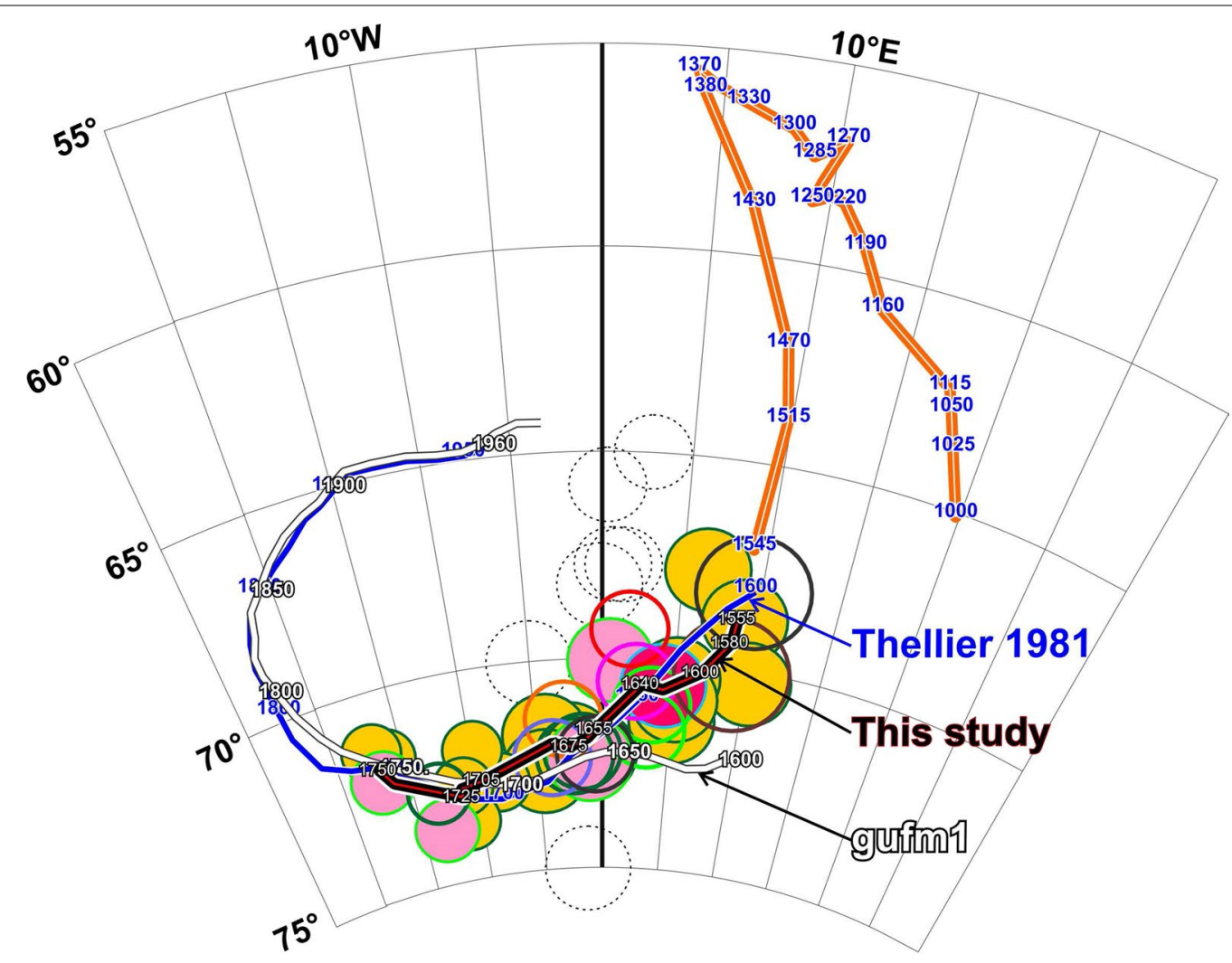

Fig. 3 Same legend as in Figs. 1 and 2, but with only the Thellier (1981) and gufm1 directional curves. The black-red curve shows the average historical geomagnetic field variation curve computed in the present study for Western Europe, after removal of seven individual D, I values (dashed white circles). See discussion in the text 
(light-green curve in Fig. 4) is in excellent agreement with our new curve, but again with a slight time delay for the directions during the sixteenth century (Fig. 4). It still shows a clear divergence with the gufm 1 curve (light-blue curve in Fig. 4). On the other hand, it is very intriguing to see that the curve derived at Rome from the regional model and transferred to the latitude of Paris using virtual geomagnetic poles (darkgreen curve in Fig. 4) is in better agreement with the gufm 1 curve derived at Paris and therefore in disagreement with most of the data discussed in "Examination of the available records" section. Such a difference between the Paris and Rome directional variation curves would indicate the existence of a significant non-dipole field effect between these two regions, while the gufm 1 model does not show any such effect (Fig. 4; e.g., Casas and Incoronato 2008). In fact, this difference arises from a mistake made for the computations of the regional model, previously highlighted by
D’Ajello Caracciolo et al. (2011). Pavón-Carrasco et al. (2009) indeed used a series of "instrumental" data from Viterbo, i.e., from the Italian magnetic observatory (see their Fig. 3 but with no reference), which actually corresponds to the values expected at this location from the gufm 1 model. It was calculated by Lanza et al. (2005) to compensate for the very small number of Italian historical data between AD 1600 and 1805 . This mistake therefore introduces a harmful interference from gufm1 into the SCHA model for the Italian region. Finally, Pavón-Carrasco et al. (2009) emphasized the existence of a possible jerk around AD 1800 (see their Fig. 10). This date is precisely at the junction between the series of "pseudo data" from Viterbo and the first real Italian geomagnetic measurements used to calculate the regional field model. The reality of a jerk at $\mathrm{AD} \sim 1800$ therefore appears doubtful.

As concluding remarks, we highlight the following points:

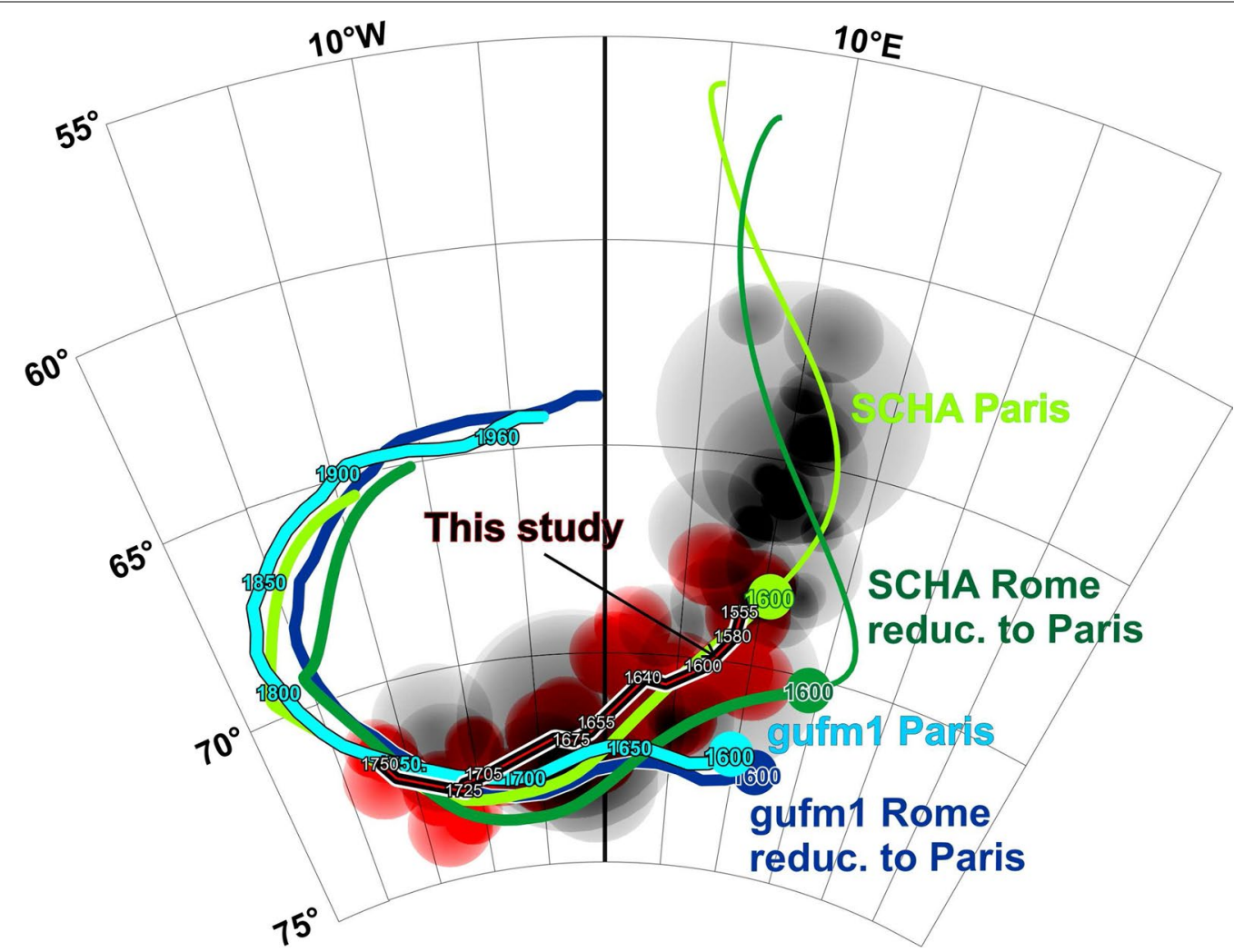

Fig. 4 Geomagnetic directional field variations in Western Europe as constrained from historical data and from two geomagnetic field models (Jackson et al. 2000; Pavón-Carrasco et al. 2009). The individual archeomagnetic results available in France between AD 1500 and 1700 are grayed out, whereas the selected instrumental measurements have a reddish tint. The average instrumental curve computed in the present study is reported in black-red. The light-blue (gufm1 Paris) and light-green (SCHA Paris) curves display the directions expected at Paris from the gufm 1 model (Jackson et al. 2000) and from the regional European geomagnetic field model constructed by Pavón-Carrasco et al. (2009), respectively. Similarly, the dark-blue (gufm1 Rome reduc. to Paris) and dark-green (SCHA Rome reduc. to Paris) curves show the directions expected at Rome after their transfer to the latitude of Paris using virtual geomagnetic poles 
- The geomagnetic directional measurements made in Western Europe before AD 1750 show an overall good consistency and define a coherent directional evolution in spite of their relatively large geographical coverage. Only a few discrepant values are identified.

- The new historical geomagnetic curve computed for Western Europe shows good agreement with the most recent segment of the French archeomagnetic directional variation curve (Bucur 1994). We therefore confirm the good consistency previously underlined by Thellier (1981) between the oldest historical magnetic measurements and the French archeomagnetic data.

- The directions expected from the gufm 1 model do not agree with the historical geomagnetic field measurements available in Western Europe for the sixteenth and most of the seventeenth century, nor with the French archeomagnetic data. This likely indicates that the older segment of gufm1 lacks reliability and that this model should be revised. A similar inference was previously made from the comparison of archeomagnetic data obtained in La Réunion Island and gufm1-derived directions (Tanguy et al. 2011). Moreover, Genevey et al. (2009) and Hartmann et al. (2011) reached the very same conclusion from archeointensity analyses carried out on ceramics from France and Brazil.

- In their current form, neither the older part of the gufm 1 model nor the recent sixteenth-eighteenthcentury segment of the regional magnetic field model constructed by Pavón-Carrasco et al. (2009) can be used for archeomagnetic dating purposes or for studies of the geomagnetic field in the past millennium.

\section{Additional file}

Additional file 1. Table S1: New averaged historical geomagnetic directions computed in Paris between the sixteenth and the mid eighteenth century. Figure S1. New historical Western European geomagnetic directional variation curve, and its comparison with the gufm 1 model.

\section{Authors' contributions}

MLG designed the study and performed the data analysis. MLG and YG discussed the data and interpretation and wrote the paper together.

\section{Acknowledgements}

We thank Jean-Claude Tanguy for stimulating recent and past discussions, Eva Fareau for her help in finding ancient documents, Suzette Roux and Michel Rival for their assistance in Latin translation. We are grateful to France Lagroix and Vincent Courtillot for a careful reading of the manuscript. We also thank F. D'Ajello Caracciolo and an anonymous reviewer for their constructive comments. This is IPGP contribution no. 3817.

\section{Competing interests}

The authors declare that they have no competing interests.
Received: 3 December 2016 Accepted: 6 February 2017

Published online: 17 February 2017

\section{References}

Aitken MJ, Hawley HN (1966) Magnetic dating — III: further archaeomagnetic measurements in Britain. Archaeometry 9:187-197

Alexandrescu M, Courtillot V, Le Mouël J-L (1996) Geomagnetic field direction in Paris since the mid-sixteenth century. Phys Earth Planet Inter 98:321-360

Alexandrescu M, Courtillot V, Le Mouël J-L (1997) High-resolution secular variation of the geomagnetic field in western Europe over the last 4 centuries: comparison and integration of historical data from Paris and London. J Geophys Res 102(B9):20245-20258

Bucur I (1994) The direction of the terrestrial magnetic field in France during the last 21 centuries. Recent progress. Phys Earth Planet Inter 87:95-109

Cabeo N (1628) Philosophia magnetica. Ferrare

Cafarella L, De Santis A, Meloni A (1992) The historical italian geomagnetic data catalogue. ING, Rome, p 160

Carlheim-Gillensköld V (1896) Sur la forme analytique de l'attraction magnétique de la Terre exprimée en fonction du temps. J. G. Wolbach Library. Provided by the NASA Astrophysics Data System

Casas L, Incoronato A (2008) Application of the relocation-error distribution on geomagnetic databases. Analyse on the "Historical Italian Geomagnetic Data Catalogue". Ann Geophys 51(4):553

Chevalier R (1925) L'aimantation des laves de l'Etna et l'orientation du champ terrestre en Sicile. Ph.D. thesis, University of Paris, Paris, France

D’Ajello Caracciolo F, Pignatelli A, Speranza F, Meloni A (2011) A re-evaluation of the Italian historical geomagnetic catalogue: implications for paleomagnetic dating at active Italian volcanoes. Solid Earth 2:65-74

Finlay CC, Aubert J, Gillet N (2016) Gyre-driven decay of the Earth's magnetic dipole. Nat Commun 7:10422

Genevey A, Gallet Y, Rosen J, Le Goff M (2009) Evidence for rapid geomagnetic field intensity variations in Western Europe over the past 800 years from new French archeomagnetic data. Earth Planet Sci Lett 284:132-143

Grandamicus PJ (1645) Nova demonstratio immobilitatis terrae petita ex virtute magnetica. Societatis I E S V, La Flêche, France

Hartmann GA, Genevey A, Gallet Y, Trindade RIF, Le Goff M, Najjar R, Etchevarne C, Afonso Holme MC (2011) New historical archeointensity data from Brazil: evidence for a large regional non-dipole field contribution over the past few centuries. Earth Planet Sci Lett 306:66-76

Holme R (2007) Large-scale flow in the core. In: Olson P (ed) In: Treatise on Geophysics, vol 8. Elsevier, Amsterdam, pp 107-130

Hulot G, Eymin C, Langlais B, Mandea M, Olsen N (2002) Small-scale structure of the geodynamo inferred from Oersted and Magsat satellite data. Nature 416:620-623

Jackson A, Jonkers A, Walker M (2000) Four centuries of geomagnetic secular variation from historical records. Philos Trans R Soc Lond A 358:957-990

Jonkers ART, Jackson A, Murray A (2003) Four centuries of geomagnetic data from historical records. Rev Geophys 41:1006

Kircher A (1641) Magnes, sive de Arte Magnetica, Opus tripartitum. Rome, Italy (at least two other editions in 1643 and 1654)

Lanza R, Meloni A, Tema E (2005) Historical measurements of the Earth's magnetic field compared with remanence directions from lava flows in Italy over the last four centuries. Phys Earth Planet Inter 148:97-107

Le Goff M (1990) Lissage et limites d'incertitude des courbes de migration polaire: pondération des données et extension bivariante de la statistique de Fisher. Comptes Rendus Acad Sci Sér II 311:1191-1198

Le Goff M, Gallet Y, Genevey A, Warmé N (2002) On archeomagnetic secular variation curves and archeomagnetic dating. Phys Earth Planet Inter 134:203-211

Mairan D (1733) Traité physique et historique de l'aurore boréale. Imprimerie Royale, Paris, France

Malin SRC, Bullard EG (1981) The direction of the Earth's magnetic field at London, 1570-1975. Philos Trans R Soc Lond 299:357-423

Pavón-Carrasco FJ, Osete ML, Torta JM, Gaya-Piqué LR (2009) A regional archeomagnetic model for Europe for the last 3000 years, SCHA.DIF.3K: applications to archeomagnetic dating. Geochem Geophys Geosyst 10:Q03013 
Tanguy J-C (1969) Sur l'aimantation des laves de l'Etna et l'orientation du champ magnétique terrestre en Sicile, de 1300 à 1800. Comptes Rendus Acad Sci Paris 268:197

Tanguy J-C, Bachèlery P, Le Goff M (2011) Archeomagnetism of Piton de la Fournaise: bearing on volcanic activity at La Réunion Island and geomagnetic secular variation in Southern Indian Ocean. Earth Planet Sci Lett 303:361-368
Thellier E (1966) Le champ magnétique terrestre fossile. Nucleus 7:1-35 Thellier E (1981) Sur la direction du champ magnétique terrestre, en France, durant les deux derniers millenaires. Phys Earth Planet Inter 24:89-132 Thomson R, Barraclough DR (1982) Geomagnetic secular variation based on spherical harmonic and cross validation analysis of historical and archaeomagnetic data. J Geomagn Geoelectr 34:245-263

\section{Submit your manuscript to a SpringerOpen ${ }^{\circ}$ journal and benefit from:}

- Convenient online submission

- Rigorous peer review

- Immediate publication on acceptance

- Open access: articles freely available online

- High visibility within the field

- Retaining the copyright to your article 